$$
\text { Conf- } 920362--25
$$

GA-A20855

\title{
SHORT WAVELENGTH INTERFEROMETER FOR ITER
}

\author{
by \\ R.T. SNIDER and T.N. CARLSTROM
}

APRIL 1992

\section{GENERAL ATOMICS}




\section{DISCLAIMER}

This report was prepared as an account of work sponsored by an agency of the United States Government. Neither the United States Government nor any agency thereof, nor any of their employees, makes any warranty, express or implied, or assumes any legal liability or responsibility for the accuracy, completeness, or usefulness of any information, apparatus, product, or process disclosed, or represents that its use would not infringe privately owned rights. Reference herein to any specific commercial product, process, or service by trade name, trademark, manufacturer, or otherwise, does not necessarily constitute or imply its endorsernent, recommendation, or favoring by the United States Government or any agency thereof. The views and opinions of authors expressed herein do not necessarily state or reflect those of the United States Government or any agency thereof. 


\title{
SHORT WAVELENGTH INTERFEROMETER FOR ITER
}

\author{
by \\ R.T. SNIDER and T.N. CARLSTROM
}

This is a preprint of a paper presented at the 9th Topical Conference on High-Temperature Plasma Diagnostics, March 16-20, 1992, Santa Fe, New Mexico, and to be printed in Review of Scientific Instruments.

Work supported by

U.S. Department of Energy

Contract No. DE-AC03-89ER51114

\section{GENERAL ATOMICS PROJECT 3466 \\ APRIL 1992}

\section{GENERAL ATOMICS misile}




\begin{abstract}
There is a need for a real time, reliable density measurement compatible with the restricted access and radiation environment on ITER. Due to the large plasma path length, high density and field, refraction and Faraday rotation effects makes the use of contemporary long wavelength $(>50 \mu \mathrm{m})$ interferometers impractical. In this paper we consider the design of a short wavelength vibration compensated interferometer which allows operation without a prohibitively large vibration isolated structure and permits the optics to be conveniently mounted directly in or on the tokamak. A density interferometer design for ITER incorporating a $10.6 \mu \mathrm{m} \mathrm{CO}_{2}$ interferometer with vibration compensation provided by a $3.39 \mu \mathrm{m}$ HeNe laser is discussed. The proposed interferometer design requires only a small intrusion into the ITER tokamak without a large support structure, refraction and Faraday rotation problems are avoided, and it provides a density resolution of at least $0.5 \%$. Results are presented from an interferometer installed on the DIII-D tokamak incorporating essential elements of the proposed ITER design including 10.6 and $3.39 \mu \mathrm{m}$ lasers, a retro-reflector mounted on the vacuum wall of the DIII-D tokamak and reai-time density feedback control.

In this paper we consider a short wavelength interferometer design that incorporates vibration compensation for use on ITER. Our primary concern is to develop a interferometer design that will produce a reliable real time density monitor. We use the ITER conceptual design activity report ${ }^{1}$ as the basis of the design.
\end{abstract}




\section{INTERFEROMETER GEOMETRY}

The port access on ITER will be severely limited. Radial viewing ports at the midplane and divertor region and tangential midplane ports are the only ports in the recent c'esign. A radial sight line would require a reflecting surface to be mounted on the inside wall. A radial array of interferometer chords could provide a full density profile measurement. While this option should be pursued, there are major technical risks associated with mounting a mirror on the inside wall, including mirror survivability and compromising the inside shield. Tangential sight lines, as shown in Fig. 1, clearly represent less technical risk but still provide a good density monitor.

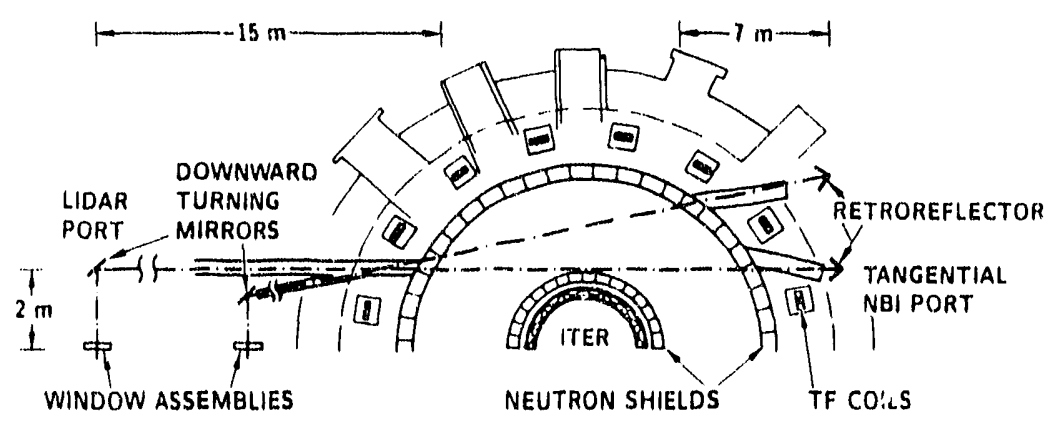

Fig. 1. Plan view of ITER showing the proposed tangential interferometer paths. 


\section{CHOICE OF WAVELENGTHS}

In considering possible wavelengths for a probing beam for a plasma density interferometer several effects must be taken into account. ${ }^{2}$ The refraction of the probing beam and Faraday rotation effects favor short wavelengths while the errors due to mechanical vibrations and density resolution favor longer wavelengths.

The variation of the angle of deviation $\left(\alpha_{\mathrm{m}}\right)$ of a $119 \mu \mathrm{m}$ beam as a function of the tangential angle of incidence $\left(\theta_{\mathrm{i}}\right)$ due to refraction, is shown in Fig. 2 for a I'TER-sized plasma with a central electron density of $1.1 \times 10^{20} \mathrm{~m}^{-3}$ for four density profile shapes. ${ }^{3}$ Also shown in $\mathrm{h}$ ig. 2 is the angular locatior of the two proposed tangential lines of sight. The refractive bending of the probing beam results in a translation of the beam at the location of the return retroreflector $(d \ell)$ which is approximately proportional to $n_{0} \lambda^{2}$ for small deviations and is plotted in Fig. 3. as a function of wavelength for three tangential angles of incidence. A beam with wavelength of $10.6 \mu \mathrm{m}$ has a maximum value of $d \ell$ less then $1 \mathrm{~mm}$ and is an order of magnitude smaller then typical beam diameters. Wavelengths above approximately $50 \mu \mathrm{m}$ experience displacements larger then $10 \mathrm{~mm}$ and would clearly have serious alignment problems.

A summary of the plasma effects expected for candidate wavelengths is shown in Table I. The large Faraday rotation is due to the large toroidal field component along the tangential path of the beam. The interference signal between the reference beam and the probing beam will go to zero (and the density measurement will be lost) when the Faraday rotation is $n \pi / 2$ with $n$ odd. Wavelengths above $100 \mu \mathrm{m}$ are expected to experience Faraday rotation shifts larger then $\pi / 2$ and are therefore unsuitable. 


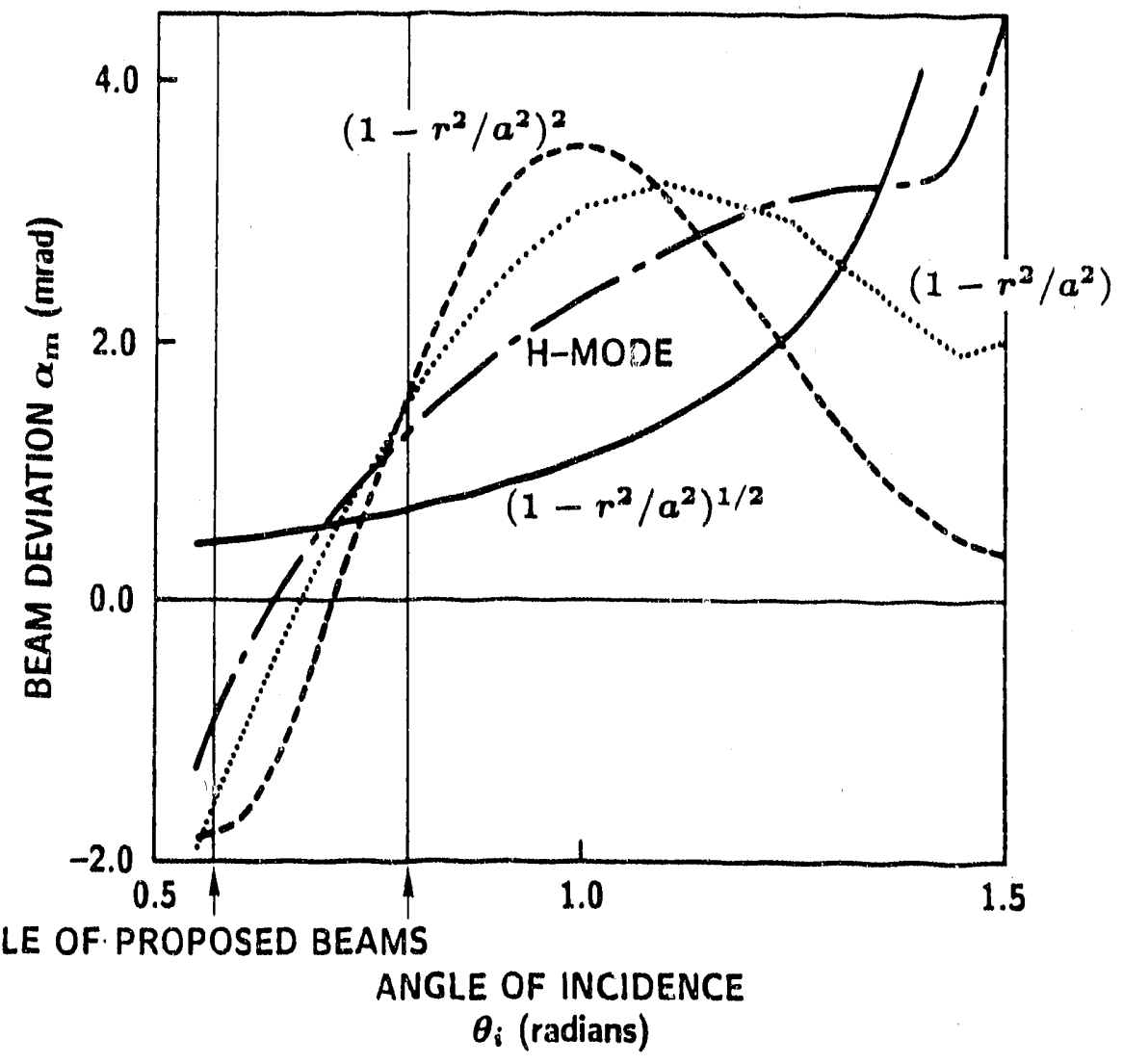

Fig. 2. The variation of the angle of deviation $\left(\alpha_{\mathrm{m}}\right)$ of a $119 \mu \mathrm{m}$ beam as a function of the tangential angle of incidence $\left(\theta_{i}\right)$ for an ITER-sized plasma with a central electron density of $1.1 \times 10^{20} \mathrm{~m}^{-3}$. The characteristic $\mathrm{H}$-mode density profile has an edge density gradient of $3.21 \times 10^{21} \mathrm{~m}^{-4}$ with constant density across the central region. 


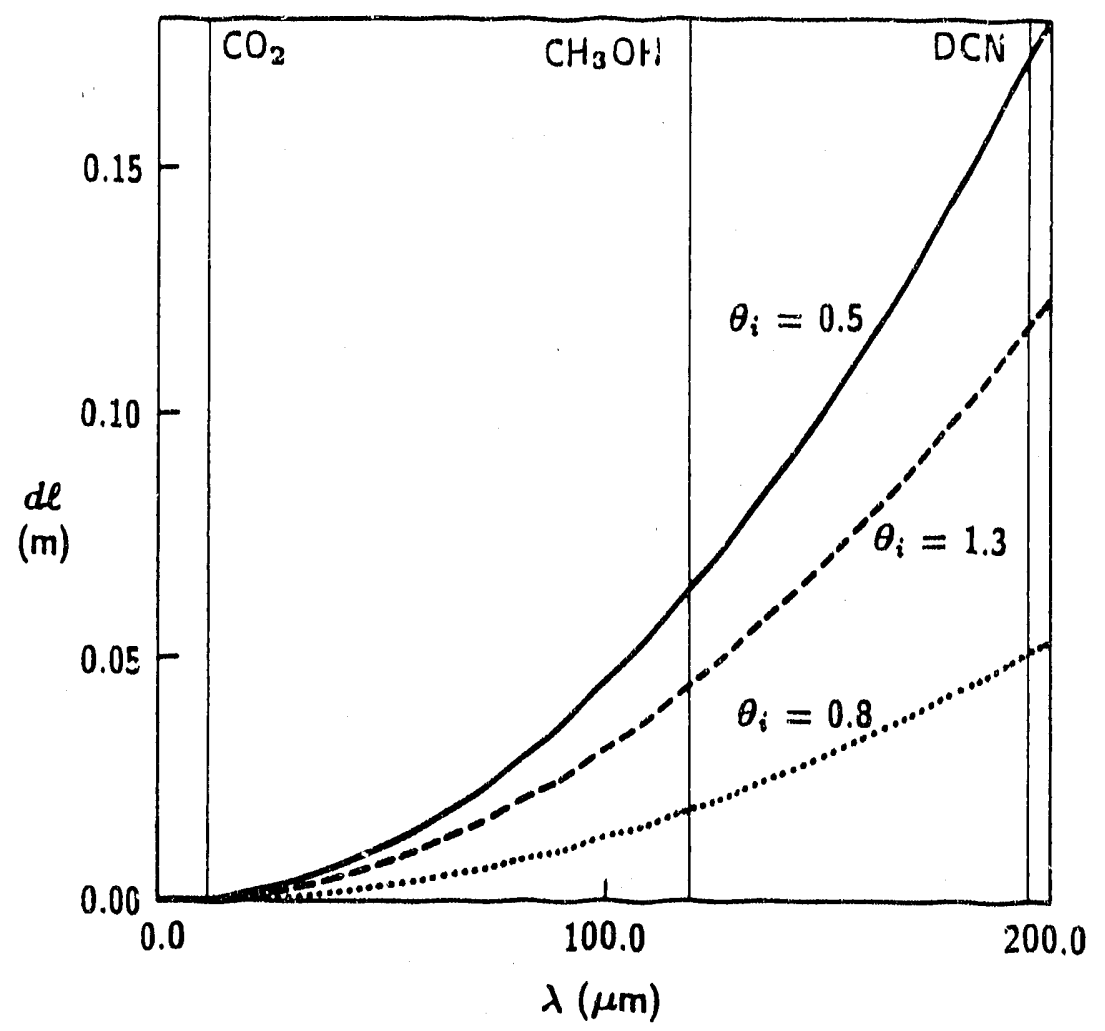

Fig. 3. The translation of a beam due to refraction at the location of the return retroreflector as a function of wavelength. 
TABLE I

SUMmary of Plasma EFFECTS For VARIOUS WAVELENGTHS

\begin{tabular}{|c|c|c|c|c|c|}
\hline $\begin{array}{c}\lambda \\
(\mu \mathrm{m})\end{array}$ & $\begin{array}{l}\text { Total } \\
\text { Fringes }\end{array}$ & $\begin{array}{c}\text { Refraction } \\
\text { Deflection } \\
\text { (mm) }\end{array}$ & $\begin{array}{l}\text { Faraday } \\
\text { Rotation } \\
\text { (radians) }\end{array}$ & $\begin{array}{c}\text { Equivale at } \\
\text { Path } \\
\text { Length }\end{array}$ & $\begin{array}{c}\Delta \bar{n} / \bar{n} \\
\left(\times 10^{-4}\right)\end{array}$ \\
\hline \multicolumn{6}{|c|}{4} \\
\hline 195 & 195 & 175 & 190 & $38 \mathrm{~mm}$ & 0.44 \\
\hline 119 & 119 & 65 & 37 & $14 \mathrm{~mm}$ & 0.7 \\
\hline 10.6 & 10 & 0.5 & 0.29 & $112 \mu \mathrm{m}$ & 8 \\
\hline
\end{tabular}




\section{VIBRATION COMPENSATION AND DENSITY RESOLUTION}

The fourth column in Table I is the displacement along the beam path of an optical component needed to produce the same phase shift as the plasma. In this design we have chosen not to have any vibration isolation structure but to mount the optics directly on the tokamak vacuum vessel or port structures and use a second wavelength interferometer to compensate for the vibrations. ${ }^{4} \mathrm{~A}$ suitable source for the vibration compensation interferometer is a $3.39 \mu \mathrm{m}$ HeNe laser. This has advantages over the $0.6328 \mu \mathrm{m}$ visible laser used in Re'erence 4 for vibration compensation in this application since the longer wavelength reduces the requirements on the optical components inside the tokamak for both flatness and surface roughness. It also increases the vibration tolerance.

The density resolution and the vibration tolerance are determined in part by the speed and accuracy of the detectors and the associated electronics. We will discuss the density resolution and the vibration tolerance expected using the specifications of the DIII-D interferometer electronics ${ }^{5}$ however improvements in the electronics can improve the results presented. The electronics on DIII-D's interferometer have a phase error of about $\pi / 50$ and can count a $2 \pi$ phase change at a rate of $1 \mathrm{MHz}$. The phase change of the laser wavefront due to mirror motion is given by $d \phi=4 \pi \Delta / \lambda$ where $\Delta$ is the distance the mirror moves along the beam path. This implies that a wall velocity of $1.7 \mathrm{~m} / \mathrm{sec}$ can be followed by the $3.39 \mu \mathrm{m}$ interferometer. At present there are no firm numbers on the ITER vessel wall motion but we can get an idea of what to expect from data from DIII-D. DIII-D data indicates a maximum vessel motion during a disruption of $1.5 \mathrm{~mm}$ and a frequency of about $20 \mathrm{~Hz}$ giving a wall velocity of $0.19 \mathrm{~m} / \mathrm{sec}$. The density sensitivity is determined by the phase error in 
the $\mathrm{CO}_{2}$ interferometer electronics. $\mathrm{A} \pi / 50$ phase error corresponds to a line average density of $7.5 \times 10^{18} \mathrm{~m}^{-3}$. At the lowest expected ITER density of $6 \times 10^{18} \mathrm{~m}^{-3}$ this provides a resolution of about $0.1 \%$. 


\section{OPTICS NEAR THE TOKAMAK}

The optics for each interferometer path near the tokamak consist of three components as shown in Fig. 1; a vacuum window, a turning mirror and a return retroreflector. The placement of these components relative to ITER has been driven by the desire to reduce the neutron flux and neutral particle sputtering and heat loads to each of the components. This placement results in a path length between the window and the return retroreflector $(z)$ of about $40 \mathrm{~m}$. The divergence and diameter of the probing beam and the path length determine the dimensions of the window and the retroreflector. ${ }^{2}$ In order to minimize the window size, the beam waist should be located at the retroreflector. The laser spot, size that contains $95 \%$ of the power at the window is $d_{\mathrm{w}}=4 \eta(\lambda z / \pi)^{1 / 2}$ while the diameter of the corresponding laser spot at the retroreflector is roughly $d r=d_{w} / \sqrt{2}$, where $\eta$ is the factor representing the increase in divergence of the laser beam above the defraction limit. The window and mirror diameters need to be twice the laser spot size to accommodate the offset return beam. Commercially available $\mathrm{CO}_{2}$ lasers are available with $\eta \simeq 2$. This implies a window diameter of $18 \mathrm{~cm}$ and a retroreflector diameter of $13 \mathrm{~cm}$.

All of the optical surfaces will require flatness of $0.85 \mu \mathrm{m}[\lambda(3.39) / 4]$ across the diameter of the component and surface roughness to be less then about $0.35 \mu \mathrm{m}$ $[\lambda(3.39) / 10]$ for the life of ITER. The retroreflector will experience a neutron flux of roughly $1.5 \times 10^{11}$ neutrons $/ \mathrm{cm}^{2} \mathrm{sec}$ and a total fluence of $1.5 \times 10^{19}$ neutrons/ $\mathrm{cm}^{2}$. The interferometer window will be subjected to a neutron flux of roughly $5 \times 10^{9}$ neutrons $/ \mathrm{cm}^{2} \mathrm{sec}$ and a total fluence of $5 \times 10^{17}$ neutrons $/ \mathrm{cm}^{2}$. In this environment a suitable window will have to maintain an acceptable transmission at both $10.6 \mu \mathrm{m}$ and $3.39 \mu \mathrm{m}$ while retaining vacuum and tritium integrity. The window will 
also be subjected to periodic baking of $350^{\circ} \mathrm{C}$. There are a number of candidate materials with good transmission at both 10.6 and $3.39 \mu \mathrm{m},{ }^{6}$ however, there has been very little neutron damage testing done on FIR materials and very few of these materials have had a tritium compatible ultra-high vacuum seal successfully attached. $\mathrm{ZnSe}$ and $\mathrm{ZnS}$ windows have good transmission properties in the region of interest and are available with hard vacuum seals in small diameters ( 1.5 in.). They have drawbacks in that they have large indices of refraction and will require anti-reflection coatings that must survive the: IT'ER environment. Further both $\mathrm{ZnSe}$ and $\mathrm{ZnS}$ darken in air at temperaitures above $250^{\circ} \mathrm{C}$. The darkening (thought to be due to oxidation) problem may be alleviated by using a. $N_{2}$ atmosphere in the beam path outside of the vacuum, although this will complicate the beam path. Despite these problems $\mathrm{ZnSe}$ and $\mathrm{ZnS}$ are the leading candidate materials for a suitable window. A third window material with good prospects for a window assembly is $\mathrm{BaF}_{2} . \mathrm{BaF}_{2}$ has excellent transmission properties and a low index of refraction and has been used in the DIII-D interferometer system with good success. $\mathrm{BaF}_{2}$ is subject to thermal shock and a suitable vacuum seal will have to be developed.

Although no neutrosi testing has been done for ITER on these materials we expect that the materials will darken or the absorption coefficient $(\alpha)$ will increase as the neutron fluence increases. Interferometry methods depe:d only on the phase information in the probing bearn and not on the absolute intensity. This means that the losses in the window can be compensated for by increasing the power of the laser beam without compromising the measurement. The limits of increasing the laser power are; available laser power and thermal stress in the window from the absorbed laser light. We can estimate the increase in the absorption cnefficient that is acceptable by considering the losses associated with the beam path shown in Fig. 1. This yields $P_{\mathrm{ab}}=\frac{P_{\mathrm{w}}\left(1-e^{-\alpha t}\right)}{\left(e^{-2 \alpha t}\right)\left(R_{\mathrm{F}}\right)^{i}}\left(1-R_{\mathrm{w}}\right) R_{0}^{n}$ where $P_{\mathrm{ab}}$ is the power absorbed in the window, $P_{\mathrm{w}}$ is the intensity of the beam at the surface of the window, $P_{\mathrm{d}}$ is the power needed at the detector to make a measurement $(S / N=10), R_{\mathrm{p}}, R_{\mathrm{w}}, R_{0}$ 
are the reflection coefficients of the internal mirrors, the front surface of the window and external components respectively, $n$ is the number of optical surfaces between the window and the detector. Typical cryogenically cooled IR detectors have $P_{\mathrm{d}}$ values of $1 \times 10^{-6}$ watts. $^{7}$ From this standpoint, as can be seen from Fig. 4, very large values of $\alpha$ are acceptable. This could considerably relax the neutron damage threshold that is acceptable for the interferometer window material.

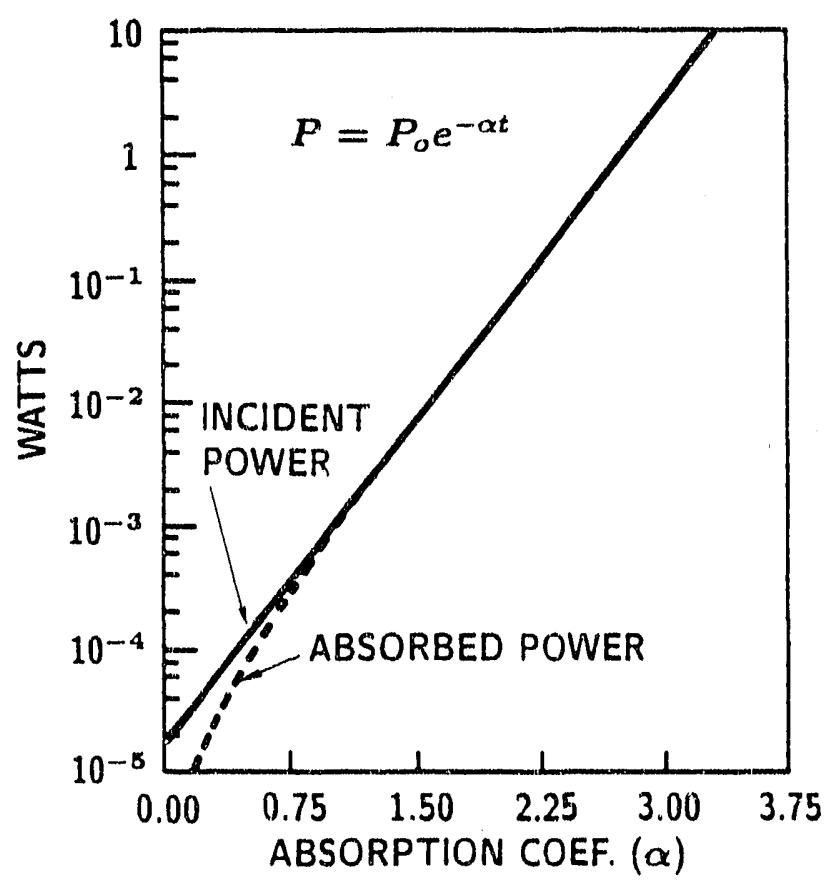

Fig. 4. Power (a) incident on the input window and ( $b$ ) absorbed in the window as a function of absorption coefficient. A detector sensitivity of $10^{-6}$ watts with a $S / N$ of 10 is assumed. 


\section{RESULTS FROM THE DIII-D INTERFEROMI:TER}

A vibration compensated interferometer using lasers i.t 10.6 and $3.39 \mu \mathrm{m}$ and a retroreflector mounted directly on the vacuum vessel has beun built and operated on the DIII-D tokamak. The radial chord of the real-time, vibration compensated $\mathrm{CO}_{2}$ interferometer on DIII- $\mathrm{D}^{5}$ was modified to use a $3.39 \mu \mathrm{m}$ HeNe laser instead of the $0.63 \mu \mathrm{m}$ HeNe laser for vibration compensation. This modification was done in odder to reduce the fringe rate caused by vibrations of a shutter assembly, installed in front of a conier cube mounted internally on the centerpost wall of the DIII-D vacuum vessel. The modification required the addition of a $6 \mathrm{~mW}, 3.39 \mu \mathrm{m}$ HeNe laser with an appropriate acousto-optic modulator, beam splitter, and detector. The other components of the interferometer remained the same, except for the density computer, which required a slight modification to accourt for the different wavelength.

The interferometer is able to make accurate density measurements in the presence of substantial vibration as shown in Fig. 5 . The interferometer can follow rapid densit; changes following ELMs $\left(3 \times 10^{15} \mathrm{~cm}^{-3} / \mathrm{sec}\right.$ at $\left.2300 \mathrm{msec}\right)$, and minor disruptions during the current rampdown phase $\left(1.5 \times 10^{16} \mathrm{~cm}^{-3} / \mathrm{sec}\right.$ at $\left.4400 \mathrm{msec}\right)$. The phase change of the $\mathrm{CO}_{2}$ signal due to vibration is about 20 times the phase change due to the plasma, indicating the need for accurate vibration compensation. During the 7 seconds the density is monitored, the noise and drift are less than $\pm 1 \times 10^{12} \mathrm{~cm}^{-3}$.

This work was supported by the U.S. Department of Energy under contract No. DE-AC03-89ER51114. 

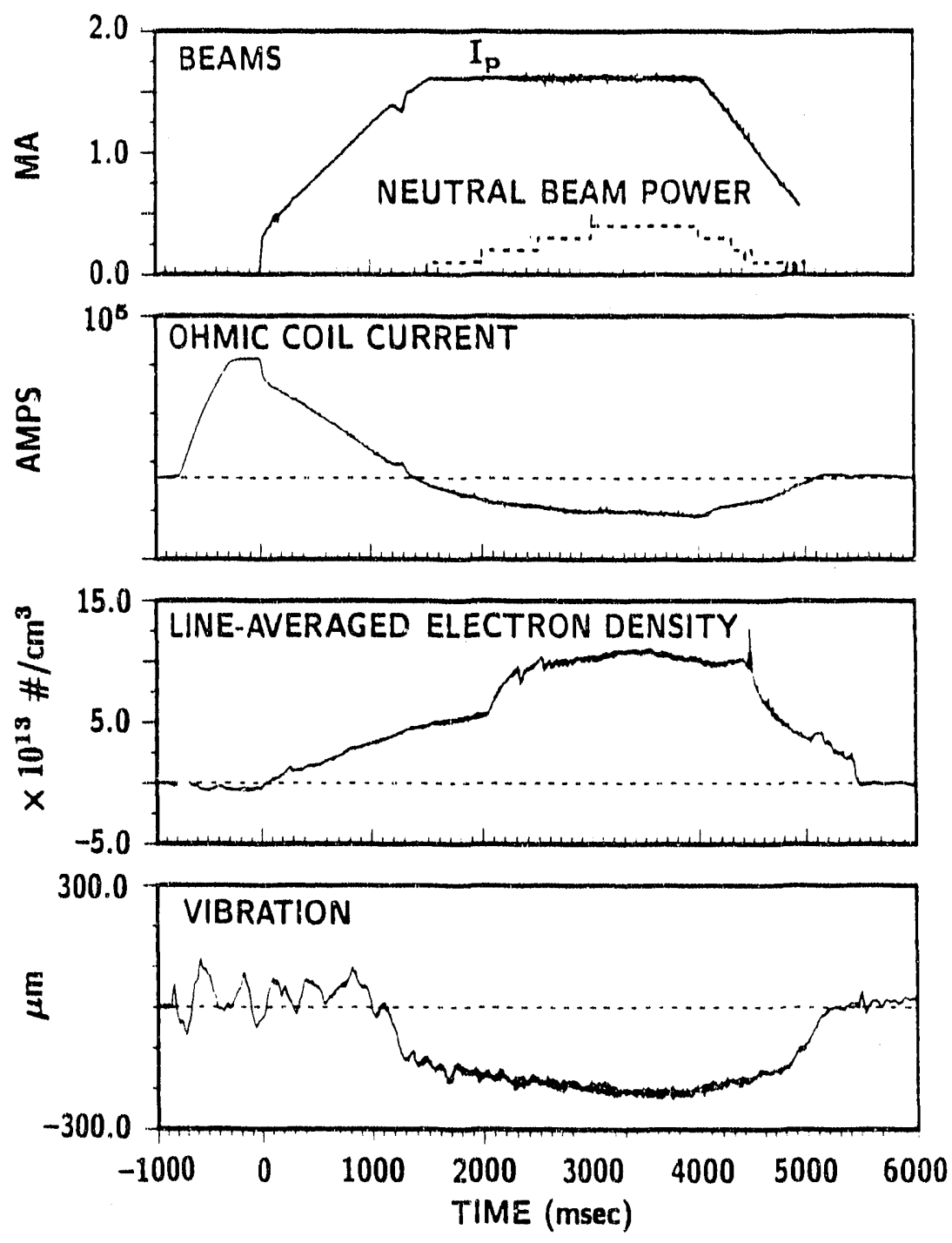

Fig. 5. Time traces of a DIII-D tokamak discharge. 


\section{REFERENCES}

1 ITER Tokamak Device, ITER Documentation Series, No. 25 (IAEA, 1991) Vienna.

2 D. Viron (1979). In "Infrared and Millimeter Waves," K.J. Button, ed., Vol. 2, New York, Academic.

3 P. Gohil, et al., Phys. Rev. Lett. 61, 1603 (1988).

4 D. R. Baker and Shu-Tso Lee, Rev. Sci. Instrum. 49, 919 (1978).

5 T. N. Carlstrom, D. R. Ahlgren, and J. Crosbie, Rev. Sci. Instrum. 59, 1063 (1988).

B G. J. Zissis, and W. L. Wolfe, "The Infrared Handbook," ERIM (1989). 

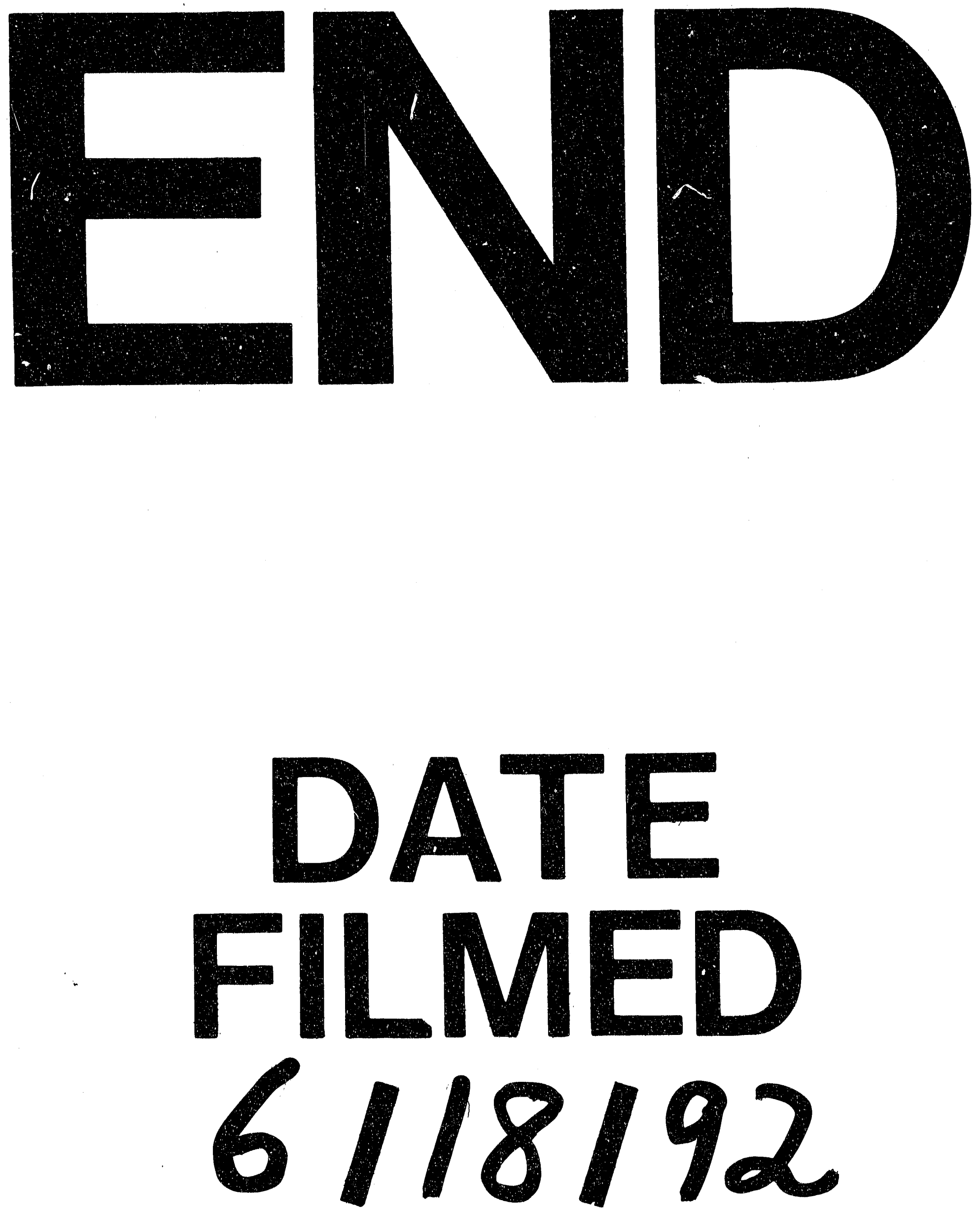
